\title{
Middle East respiratory syndrome coronavirus: epidemic potential or a storm in a teacup?
}

\author{
Alimuddin I. Zumla ${ }^{1,2,3}$ and Ziad A. Memish ${ }^{3,4,5}$
}

Affiliations: 'Division of Infection and Immunity, University College London, London, and ${ }^{2} \mathrm{NIHR}$ Biomedical Research Centre, UCL Hospitals NHS Foundation Trust, London, UK. ${ }^{3}$ Global Center for Mass Gatherings Medicine, Ministry of Health, Riyadh, ${ }^{4}$ Ministry of Health, Riyadh, and ${ }^{5}$ Alfaisal University, Riyadh, Kingdom of Saudi Arabia.

Correspondence: Z.A. Memish, Ministry of Health and Alfaisal University, Riyadh 11176, Kingdom of Saudi Arabia. E-mail: zmemishdyahoo.com

@ERSpublications

MERS coronavirus: potential pandemic or storm in a teacup? http://ow.ly/ttpki

The Middle East respiratory syndrome (MERS) is a new killer respiratory disease caused by the MERS coronavirus (CoV) first reported from the Kingdom of Saudi Arabia (KSA) in September 2012, after identification of a novel betacoronavirus from a Saudi Arabian patient who died from a severe respiratory illness [1,2]. Retrospective study of stored samples later showed that, earlier in April 2012, a cluster of severe respiratory illness occurred in a public health hospital in Zarqa, Jordan, where eight healthcare workers (HCWs) were among the 11 people affected, with two deaths attributed to MERS-CoV [3]. The appearance of any new fatal infectious disease, and uncertainty about its origin and mode of transmission, invariably threatens global health security and its detection in western countries rapidly focuses political and scientific attention. Unfortunately, at the same time, it evokes unnecessary and unwarranted fierce scientific competition and discourse, as was illustrated by the HIV, severe acute respiratory syndrome (SARS) and avian influenza epidemics [4-8]. Disappointingly, the events surrounding the MERS-CoV have been no different [6]. MERS-CoV was first isolated, sequenced and patented by Erasmus Medical Centre (EMC) researchers in Rotterdam, the Netherlands, and initially it was named after their centre as HCoV-EMC [2]. Subsequently, international consensus led to renaming it as MERS-CoV [9].

Since the first KSA case report in September 2012, the KSA Ministry of Health (MoH) has recommended mandatory testing for MERS-CoV in all cases of respiratory illness requiring intensive care admission. 6 months after MERS-CoV was discovered, at the end of March 2013, there were only 17 MERS-CoV cases reported globally, nine of which were from KSA [10], four of these from one family case cluster [11]. This small number of MERS-CoV cases would not have attracted much global attention had it not been for the high mortality rate in persons who contracted the disease, all of whom had medical comorbidities [9]. Frenzied media reports followed the detection of MERS cases in the UK [11-13], France [14], Germany [15-17] and Italy [18], and focussed international attention. The media scaremongering and hype led to exaggerated claims of the potential threat of MERS-CoV to global health security.

A flurry of scientific, political and media activity ensued, with global attention focussed on the pandemic potential of MERS-CoV. This had become particularly urgent and important in light of an estimated 2 million pilgrims from over 182 countries expected to visit Makkah and Madinah, KSA, to perform the

Received: Dec 282013 | Accepted after revision: Jan 092014 | First published online: March 132014

Support statement: A. Zumla acknowledges support from the National Institute of Health Research Biomedical Research Centre, University College London Hospitals, the European and Developing Countries Clinical Trials Partnership, the Hague and the European Community Seventh Framework Programme for Research.

Conflict of interest: None declared.

Copyright @ERS 2014 
October 2013 annual hajj pilgrimage. As of April 1, 2013, there were only small numbers of MERS cases and obtaining meaningful research data was limited only to case reports [2, 11-19]. The KSA and other Middle Eastern governments kept proactive, watchful surveillance with immediate reporting to the World Health Organization (WHO) of MERS cases. There were many unknowns at that time regarding MERS-CoV. Several priority research questions required urgent answers: the source of the virus; the route of transmission; infectious potential; the epidemiological and clinical features; occurrence in the community; transmission patterns; and evolution of the virus. A lack of accurate, sensitive and specific rapid serological diagnostic tests for surveillance hindered the conduct of case-control studies. The epidemiology, mode of transmission, clinical spectrum of illness and incidence in the community remained largely unknown.

From late April to May 2013, reports of an outbreak at the Al-Hasa healthcare facilities in the eastern province of KSA changed the pace of research, and answered all unwarranted political and media criticisms. For the Al-Hasa hospital outbreak, urgent research conducted under the umbrella of the Global Centre for Mass Gatherings Medicine at the KSA MoH in Riyadh to enhance equitable global research and development partnerships rapidly brought together UK, US, Canadian and Saudi researchers who defined transmission patterns through hospital epidemiological studies and sequencing of the MERS-CoV isolates within a period of 4 weeks [20-22]. These studies suggested that aerosol transmission appeared to be the likely route of human-to-human transmission of MERS-CoV in hospitals and that those with medical comorbidities suffered a higher death rate [21]. There are similarities and differences between the clinical and laboratory features of MERS-CoV infections when compared to that of SARS-CoV infections [21, 23, 24]. SARS originated as an unusual and atypical pneumonia in Guangdong Province in southern mainland China in November 2002, spread to Hong Kong and rapidly transmitted worldwide (26 countries over five continents), resulting in nearly 8000 cases with just over 900 deaths [23]. In striking contrast, only 175 MERS cases have been diagnosed in the past 20 months globally, with very limited spread outside the Arabian peninsula countries (KSA, Jordan, the United Arab Emirates (UAE), Qatar, Oman and Kuwait). This highlights the very low human-to-human transmissibility of MERS-CoV when contrasted to SARS-CoV. The presenting clinical symptoms, signs and imaging features of MERS-CoV disease are similar to those seen in SAR (table 1) [21]. Fever, cough and dyspnoea are the major symptoms of patients admitted to hospital. Other presenting symptoms include chills, malaise, rigor, headache, myalgia and malaise. While respiratory failure is a major clinical feature of MERS-CoV infection, atypical presentation with diarrhoea has been reported in both MERS and SARS. Common admission imaging and laboratory features of SARS and MERS on admission to hospital include infiltrates on chest radiographs and lymphopenia, and thrombocytopenia and elevated liver enzymes have been noted in some cases [21, 23]. There is no specific treatment yet, although several treatment options used in the SARS epidemic are recommended and other therapies are under development.

Initial MERS case reporting was biased, as it was the more severe cases with serious life-threatening respiratory disease requiring hospitalisation and intensive care that were the centre of attention and were screened for MERS-CoV. Thus, initial data showed a high mortality rate of up to $65 \%$ and indicated that MERS-CoV primarily affected individuals with comorbid conditions such as diabetes and chronic renal failure [20, 21]. As more data became available, a spectrum of MERS-CoV infection from asymptomatic and mild cases to those rapidly fulminant has been noted [24]. A quarter of patients are reported to have accompanying gastrointestinal symptoms, including diarrhoea and vomiting, and comorbid chronic underlying medical conditions [21]. The report of the case from the UK [12] showed that siblings who are not immunocompromised only manifest mild respiratory illnesses, and do not require hospitalisation. Screening of 33 close contacts ( 20 household and 13 non-household) found there were only two cases $(6 \%$ attack rate) of confirmed MERS-CoV infection, one with mild illness and one with severe illness. There were no cases of MERS-CoV infections among $59 \mathrm{HCWs}$ who nursed the index case without full personal protective equipment $[12,13]$.

In light of the continued media attention on the high mortality rate, and the continuing sporadic and intermittent detection of MERS-CoV cases, particularly the healthcare-related outbreak at Al-Hasa [20-22], WHO convened an emergency committee in July 2013 under the International Health Regulations to advise the Director-General on the status of the MERS-CoV situation [24]. The emergency committee comprises international experts from all WHO regions and collates available information, using a risk-assessment approach decide whether conditions for a public health emergency of international concern are met or not. The critical question at that time was whether MERS-CoV was going to progress to cause a major pandemic as did SARS or was it just a "storm in a teacup" that it would die out, requiring only surveillance and reassurance?

Subsequent surveillance performed by the KSA MoH indicates that MERS-CoV affects both sexes and, although only a few cases of MERS-CoV in children have been detected, it remains mainly a disease of adults across all age groups [24-27]. In KSA, we have subsequently identified milder or asymptomatic cases of MERS in HCWs, 


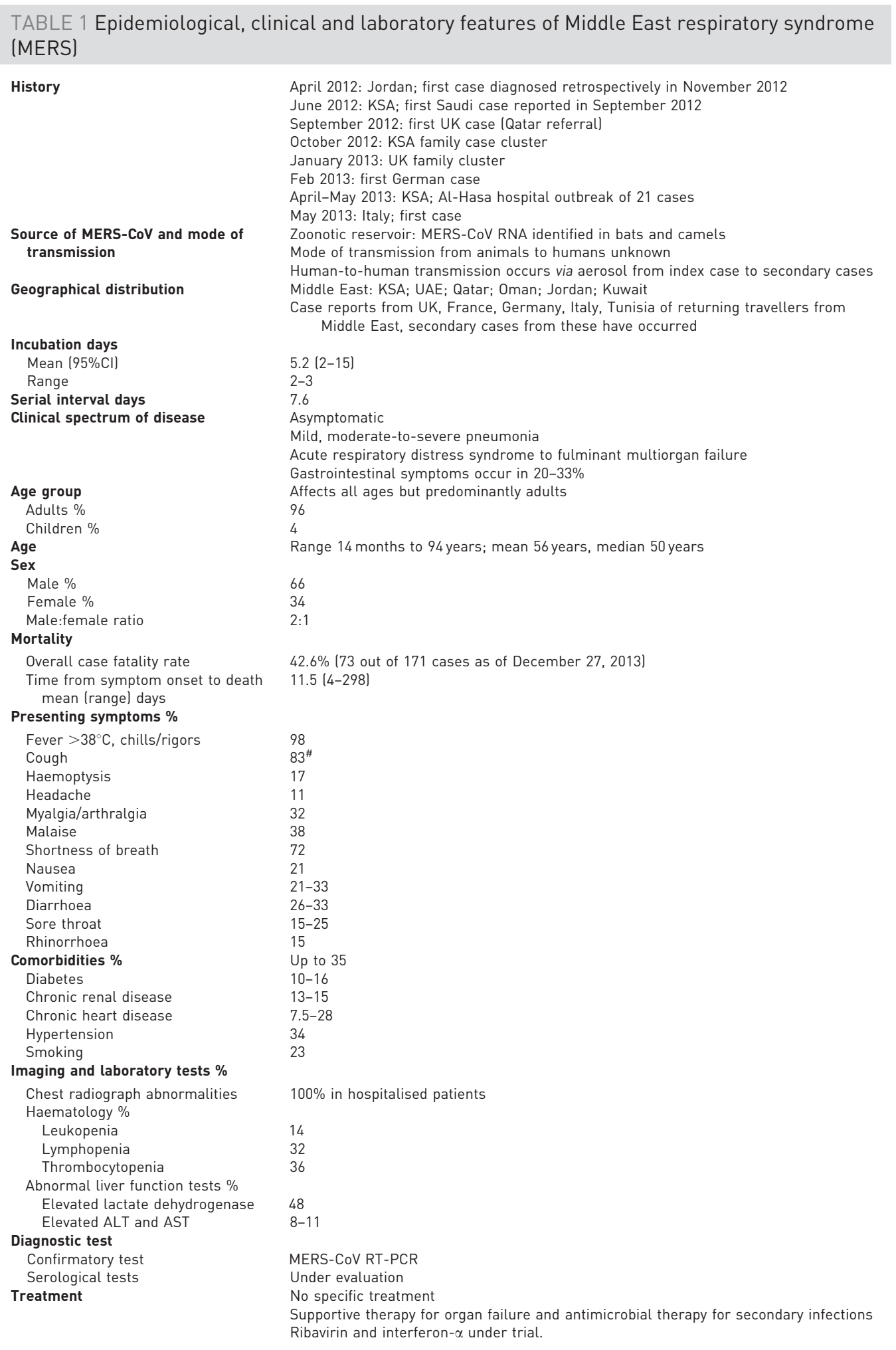

KSA: Kingdom of Saudi Arabia; CoV: coronavirus; UAE: United Arab Emirates; ALT: alanine aminotransferase; AST: aspartate transaminase. "\#: $56 \%$ dry cough and $44 \%$ productive cough. Data from $[2,3,12,14-21,24]$.

children and family members in contact with MERS cases [24, 26], illustrating that there is a whole spectrum of undiagnosed asymptomatic or milder forms of clinical disease. An increasing number of asymptomatic HCWs are now being identified and reported to the WHO $[27,28]$. Standard contact respiratory precautions during 
routine care and airborne precautions during invasive respiratory procedures are recommended by WHO for management of in-patients with known or suspected MERS-CoV infection [29].

A critical question which remains unanswered is the source and mode of transmission to humans of MERS$\mathrm{CoV}$. The occurrence of MERS cases in multiple regions and provinces (fig. 1) in KSA as well as in other neighbouring countries, such as Jordan, Qatar, Kuwait, Oman and UAE, means a more widespread population of MERS-CoV in animals or humans must exist. Zoonotic transfer from an animal reservoir to humans has been shown to occur with the SARS-CoV $[30,31]$. The quest to find an animal source for MERS$\mathrm{CoV}$ [32-34] continues. Serological evidence for a cross-reactive virus in camels has been reported (fig. 2) and a small fragment of MERS-CoV sequence have been identified in a bat from KSA [34]. Recent identification of MERS-CoV in two camels in Qatar [35] lends support to the previous assumption that an animal source of the route of transmission could be either direct contact, consumption of a contaminated food product or even contact with a contaminated fomites. The KSA MoH is pursuing a vigorous search for the source of MERS$\mathrm{CoV}$ in animal hosts and other potential reservoirs, and their transmission routes to humans.

Whole-genome sequencing of MERS-CoV isolates from clinical samples from MERS cases diagnosed from across KSA has allowed the study of the phylogenetic relationships and evolution of the virus [20, 35]. Our study of MERS-CoV genomes from KSA MERS patients show three genetically distinct lineages of MERS$\mathrm{CoV}$ circulating in Riyadh and it is unlikely that the KSA infections are the result of a single continuous human-to-human transmission chain. While careful monitoring of MERS-CoV genome evolution will continue, the likelihood of an impending global epidemic based on current genomic data appears unlikely. MERS-CoV genomes obtained from respiratory tract samples of all confirmed KSA MERS-CoV cases are being sequenced. These will provide valuable insights into the understanding of the molecular characteristics and transmission dynamics of MERS-CoV, defining species specificity, ascertaining mutation rates and virulence, and enabling the discovery of new drug targets, novel drugs, diagnostics and vaccines.

As of December 27, 2013, worldwide, 20 months since the first discovery of MERS-CoV in Jeddah, KSA, there have been a total of 171 cases of MERS-CoV infection with 73 deaths (42.6\% mortality) reported to the WHO [34]. The trend in case detection rate does not suggest that an impending epidemic is inevitable. The majority of cases (141 and 57 deaths (40\%) have been reported from KSA [36]. All cases are linked to only six countries in the Middle East: KSA, Jordan, Kuwait, Oman, Qatar and UAE. Five countries outside the Arabian Peninsula (France, Italy, Germany, Tunisia and the UK) have detected MERS cases that were either transferred for care or travellers returning from one of the Middle East countries and subsequently became ill [12-18]. Four countries (Italy, France, Tunisia and the UK) have reported endemic secondary cases arising from local transmission linked to the initial imported case. The clusters in Italy [18], the UK [13], France [14] and Tunisia [24] have been linked to infection from a returning traveller and transmission

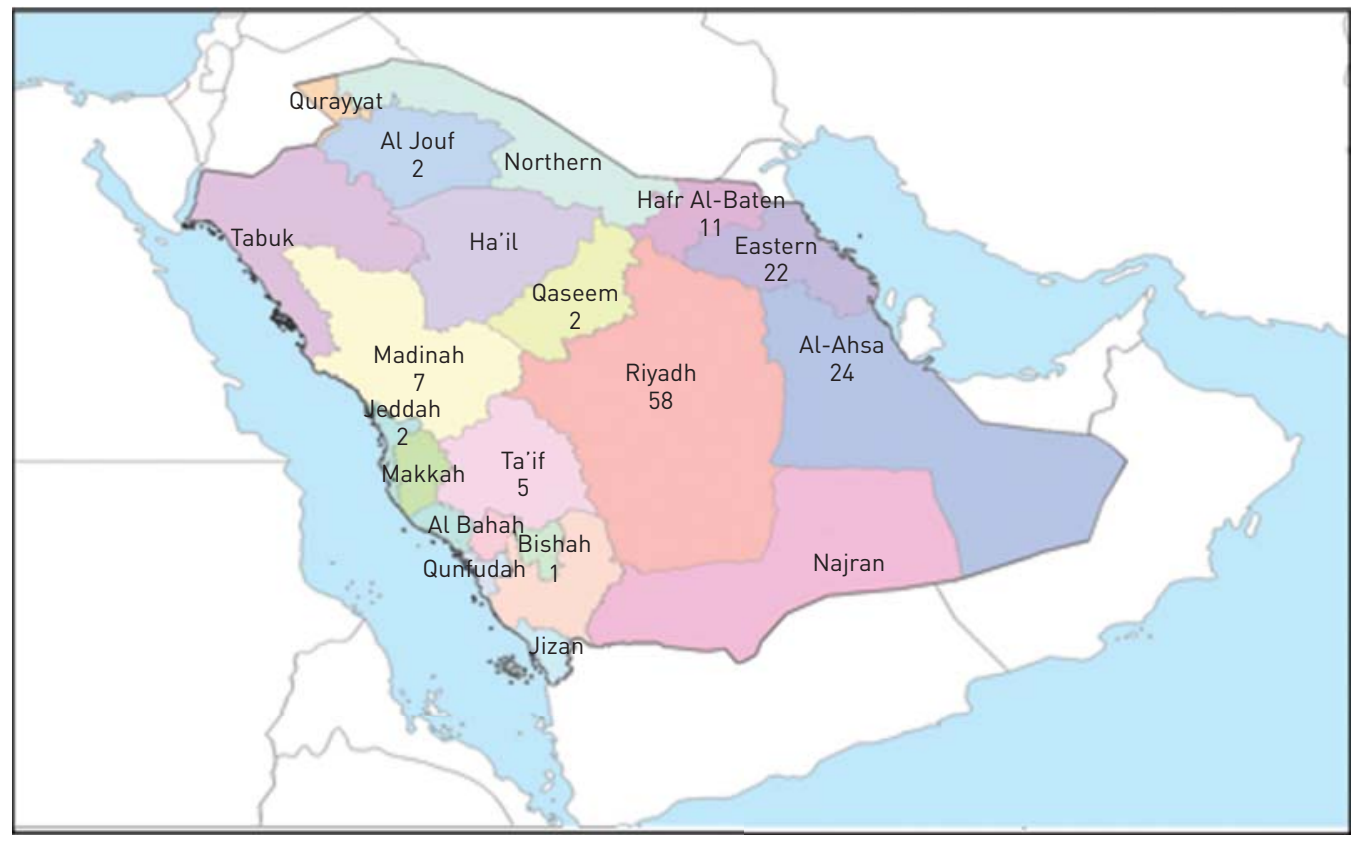

FIGURE 1 Middle Eastern respiratory syndrome coronavirus cases reported in the Kingdom of Saudi Arabia since September 2012 by region and province. 
FIGURE 2 Camels: a possible intermediary source of Middle Eastern respiratory syndrome coronavirus.

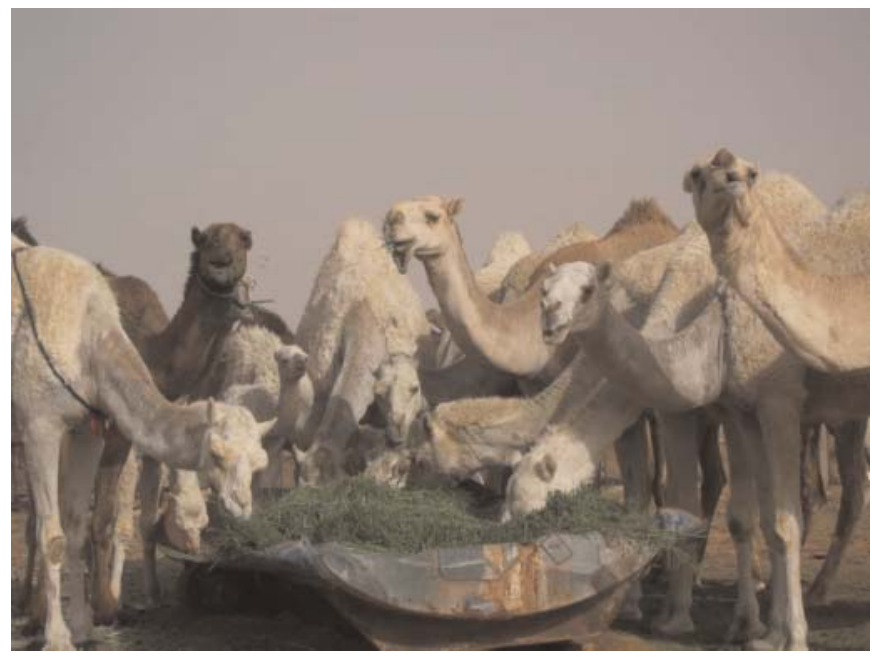

has only occurred in certain settings, in particular, family and healthcare facilities. There is still no evidence of sustained community transmission to date.

So, what is the potential of MERS-CoV to cause a pandemic? When first discovered over 18 months ago, it was unknown whether MERS-CoV would remain a disease restricted to the Middle East, with intermittent, sporadic outbreaks, or progress to becoming a global pandemic, or burn out with time. Despite extensive investigation and testing of several thousand contacts and suspected cases by the KSA MoH, only a few instances of transmission to healthcare workers or family contacts have been identified [24]. Almost all patients who died or were hospitalised had severe disease and comorbid medical conditions [24]. The mortality rate and severity of disease are exaggerated to some degree by detection of such cases. The casefatality rate has fallen in recent months due to the detection of milder and asymptomatic cases [24]. The most critical characteristic of pandemic MERS-CoV strains would be progression to efficient human-tohuman transmission. The number of sporadic MERS cases being reported has been small and indicates that the virus appears not to be readily capable of rapid human-to-human transmission. Rapid identification and isolation of cases combined with a basic reproduction number $(R 0)<1$ may control the human-tohuman transmission, as long as the virus transmission properties remain the same.

Mathematical modelling by BREBER et al. [37] indicate that $R 0$ (the number of secondary cases each index patient is expected to infect in a fully susceptible population) of the MERS-CoV is 0.69 in the worst-case scenario and 0.60 in a more optimistic scenario, concluding that MERS-CoV does not yet have pandemic potential, which would occur if $R 0$ had reached 1 . The analysis shows that the chance of MERS-CoV having $R_{0}>1$ is extremely small. Thus, it appears from current evidence that it is most unlikely that MERS-CoV will follow a path similar to that of SARS. MERS-CoV has been circulating in humans for $\geqslant 20$ months without a massive increase in the numbers of cases. As of November 2013, >5000 KSA individuals (inpatients with respiratory infections, healthcare workers and family contacts of confirmed MERS patients) have been screened for the presence of MERS-CoV and yet no significant increase in case detection rates has been observed. 2 million pilgrims from $>180$ countries and 1 million local KSA pilgrims have very recently visited Makkah and Madinah to perform the annual hajj pilgrimage in October 2013 [38]. All these pilgrims have returned home after stay of between 2 and 8 weeks without a single confirmed MERS case being reported from within KSA or from their home countries. While many priority research questions remain to be answered before the true pandemic potential and global impact of MERS-CoV can be accurately determined [39], MERS-CoV may turn out to be a storm in a teacup.

\section{Acknowledgements}

We acknowledge the support of KSA MoH and the Global Centre for Mass Gatherings Medicine board members, and all KSA physicians and laboratory personnel involved in our research studies.

\section{References}

1 Severe respiratory illness associated with a novel coronavirus - Saudi Arabia and Qatar, 2012. MMWR Morb Mortal Wkly Rep 2012; 61: 820.

2 Zaki AM, van Boheemen S, Bestebroer TM, et al. Isolation of a novel coronavirus from a man with pneumonia in Saudi Arabia. N Engl J Med 2012; 367: 1814-1820.

3 Hijawi B, Abdallat M, Sayaydeh A, et al. Novel coronavirus infections in Jordan, April 2012: epidemiological findings from a retrospective investigation. East Mediterr Health J 2013; 19: Suppl. 1, S12-S18. 
Abbott A, Brumfiel G. Nobel for AIDS virus discovery, finally. Nature 2008; 455: 712-713.

Kupferschmidt K. As outbreak continues, confusion reigns over virus patents, http://news.sciencemag.org/peopleevents/2013/05/outbreak-continues-confusion-reigns-over-virus-patents Date last accessed: December 15, 2013. Date last updated: May 28, 2013.

6 Cascio J. Viropiracy, www.openthefuture.com/2008/08/viropiracy.html Date last accessed: December 21, 2013. Date last updated: August 26, 2008.

7 Tsang KW, Ooi GC, Ho PL. Diagnosis and pharmacotherapy of severe acute respiratory syndrome: what have we learnt? Eur Respir J 2004; 24: 1025-1032.

$8 \quad$ Woodhead MA, Torres A, Ewig S. Pigs might fly. Eur Respir J 2009; 33: 1241-1243.

9 De Groot, RJ. Baker, SC. Baric, et al. Middle East respiratory syndrome coronavirus (MERS-CoV): announcement of the Coronavirus Study Group. J Virol 2013; 87: 7790-7792.

10 World Health Organization. MERS-CoV summary and literature update www.who.int/csr/disease/coronavirus infections/update_20130620/en/index.html Date last accessed: December 27, 2013. Date last updated: June 20, 2013. Memish ZA, Zumla AI, Al-Hakeem RF, et al. Family cluster of Middle East respiratory syndrome coronavirus infections. N Engl J Med 2013; 368: 2487-2494.

12 Health Protection Agency (HPA) UK Novel Coronavirus Investigation team. Evidence of person-to-person transmission within a family cluster of novel coronavirus infections, United Kingdom, February 2013. Euro Surveill 2013; 18: 20427.

13 Bermingham A, Chand MA, Brown CS, et al. Severe respiratory illness caused by a novel coronavirus, in a patient transferred to the United Kingdom from the Middle East, September 2012. Euro Surveill 2012; 17: 20290.

14 Mailles A, Blanckaert K, Chaud P, et al. First cases of Middle East Respiratory Syndrome Coronavirus (MERS-CoV) infections in France, investigations and implications for the prevention of human-to-human transmission, France, May 2013. Euro Surveill 2013; 18: 20502.

15 Guery B, Poissy J, el Mansouf L, et al. Clinical features and viral diagnosis of two cases of infection with Middle East Respiratory Syndrome coronavirus: a report of nosocomial transmission. Lancet 2013; 381: 2265-2272.

16 Drosten C, Seilmaier M, Corman VM, et al. Clinical features and virological analysis of a case of Middle East respiratory syndrome coronavirus infection. Lancet Infect Dis 2013; 13: 745-751.

17 Buchholz U, Muller MA, Nitsche A, et al. Contact investigation of a case of human novel coronavirus infection treated in a German hospital, October-November 2012. Euro Surveill 2013; 18: 20406.

18 Puzelli A, Azzi MG, Santini A, et al. Investigation of an imported case of Middle East Respiratory Syndrome coronavirus (MERS-CoV) infection in Florence, Italy, May to June 2013. Euro Surveill 2013; 18: 20564.

19 Albarrak AM, Stephens GM, Hewson R et al. Recovery from severe novel coronavirus infection. Saudi Med J 2012; 33: $1265-1269$.

20 Assiri A, McGeer A, Perl TM, et al. Hospital outbreak of Middle East respiratory syndrome coronavirus. $N$ Engl J Med 2013; 369: 407-416.

21 Assiri A, Al-Tawfiq JA, Al-Rabeeah AA, et al. Epidemiological, demographic, and clinical characteristics of 47 cases of Middle East respiratory syndrome coronavirus disease from Saudi Arabia: a descriptive study. Lancet Infect Dis 2013; 13: 752-761.

22 Cotten M, Watson SJ, Kellam P, et al. Transmission and evolution of the Middle East respiratory syndrome coronavirus in Saudi Arabia: a descriptive genomic study. Lancet 2013; 382: 1993-2002.

23 Peiris J, Yuen KY, Osterhaus AD, et al. The severe acute respiratory syndrome. N Engl J Med 2003; 349: 2431-2441.

24 The WHO MERS-CoV Research Group. State of knowledge and data gaps of Middle East Respiratory Syndrome coronavirus (MERS-CoV) in humans. PLoS Curr 2013; 5: ecurrents.outbreaks.0bf719e352e7478f8ad85fa30127ddb8.

25 Chan M. Middle East respiratory syndrome coronavirus (MERS-CoV), www.who.int/ihr/procedures/statements 20130709/en/index.html Date last accessed: December 27, 2013. Date last updated: July 9, 2013.

26 Omrani AS, Matin MA, Haddad Q, et al. A family cluster of Middle East Respiratory Syndrome Coronavirus infections related to a likely unrecognized asymptomatic or mild case. Int J Infect Dis 2013; 17: e668-e672.

27 Penttinen PM, Kaasik-Aaslav K, Friaux A, et al. Taking stock of the first 133 MERS coronavirus cases globally - Is the epidemic changing? Euro Surveill 2013; 18: 20596.

28 Memish ZA, Zumla AI, Assiri A. Middle East respiratory syndrome coronavirus infections in health care workers. N Engl J Med 2013; 369: 884-886.

29 World Health Organization. WHO Statement on the Second Meeting of the IHR Emergency Committee concerning MERS-CoV. www.who.int/mediacentre/news/statements/2013/mers_cov_20130717/en/ Date last accessed: August 14, 2013. Date last updated: July 17, 2013.

30 To KK, Hung IF, Chan JF, et al. From SARS coronavirus to novel animal and human coronaviruses. J Thorac Dis 2013; 5: Suppl. 2, S103-S108.

31 Osterhaus AD, Fouchier RA, Kuiken T. The aetiology of SARS: Koch's postulates fulfilled. Philos Trans R Soc Lond B Biol Sci 2004; 359: 1081-1082.

32 Reusken CB, Haagmans BL, Müller MA, et al. Middle East respiratory syndrome coronavirus neutralising serum antibodies in dromedary camels: a comparative serological study. Lancet Infect Dis 2013; 13: 859-866.

33 Aburizaiza AS, Mattes FM, Azhar EI, et al. Investigation of anti-MERS-coronavirus antibodies in blood donors and abbatoir workers in Jeddah and Makkah, Kingdom of Saudi Arabia, fall 2012. J Infect Dis 2014; 209: 243-246.

34 Memish ZA, Mishra N, Olival KJ, et al. Middle East respiratory syndrome coronavirus in bats, Saudi Arabia. Emerg Infect Dis 2013; 19: 1819-1823.

35 Haagmans BL, Al Dhahiry SH, Reusken CB, et al. Middle East respiratory syndrome coronavirus in dromedary camels: an outbreak investigation. Lancet Infect Dis 2014; 14: 140-145.

36 World Health Organization. Middle East respiratory syndrome coronavirus (MERS-CoV) - update. www.who.int/ csr/don/2013_12_27/en/index.html Date last accessed: December 27, 2013. Date last updated: December 27, 2013.

37 Breban R, Riou J, Fontanet A. Interhuman transmissibility of Middle East respiratory syndrome coronavirus: estimation of pandemic risk. Lancet 2013; 382: 694-699.

38 Memish ZA, Al-Rabeeah AA. Public health management of mass gatherings: the Saudi Arabian experience with MERS-CoV. Bull World Health Organ 2013; 91: 899-899A.

39 Hui DS, Zumla A. Advancing priority research on the middle East respiratory syndrome coronavirus. J Infect Dis 2014; 209: 173-176. 